\title{
Plastic Surgery of the Anaesthetic Foot of Leprosy
}

\author{
W. M. LENNOX, B.Sc., F.R.C.s.(ENG.), F.R.G.s.(EDIN.), \\ Department of Orthopaedics, C.M.C. Hospital, Vellore).
}

Some of the orthopaedic principles governing the correction of leprosy foot deformity have been discussed. Even when the orthopaedic condition of the foot is satisfactory, ulcers may occur when the quality of tissue between the bone and ground (or shoe) is poor. The normal sole contains a highly specialised superficial fascia which is a fibrous microcellular structure filled with fat (Maisels). A sheet of this tissue extends from the pulps of the toes anteriorly to the lower third of the back of the calcaneum behind, and laterally for about $\frac{2}{3}$ of an inch $(2 \mathrm{~cm}$.) round the lateral and medial borders of the foot. The layer is thickened under the metatarsal heads and under the heel. The fascia occurs in sufficient thickness in non-weightbearing areas to form a useful reserve of tissue for transfer to strategic sites when trophic ulcers destroy or distort the shock absorbing mechanism.
Every ulcer leaves a scar and every scar increases the susceptibility of the foot to further ulcers. In certain cases a scarred foot fails to obtain sufficient protection from its shoe, and scars break down in spite of the best efforts of the shoemaker. A scar which breaks down when the patient walks is known as an 'unstable' scar, and this event is an indication for plastic surgery. It is the purpose of this paper to describe the principles which we follow in the management of these cases. Our object is to render unstable scars safe for walking with the protection of a microcellular rubber shoe.

Our experience has led us to recognise certain sites and types of scars which are particularly liable to cause trouble, even in the relatively normal foot. In the deformed foot a scar on a weight bearing area is almost certain to ulcerate. The first line of treatment is correction of the deformity. Thereafter attention is directed to

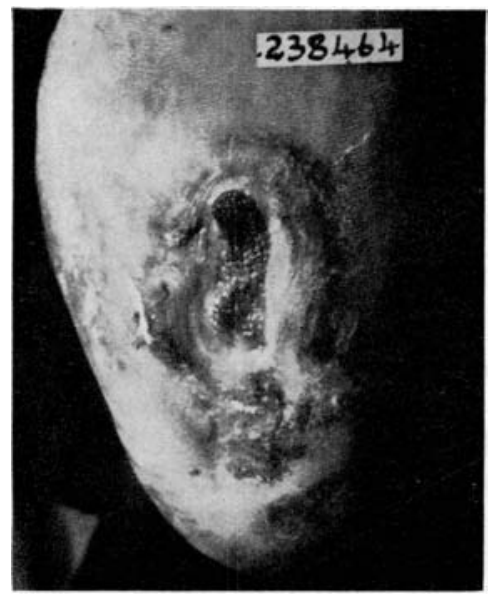

FIG I

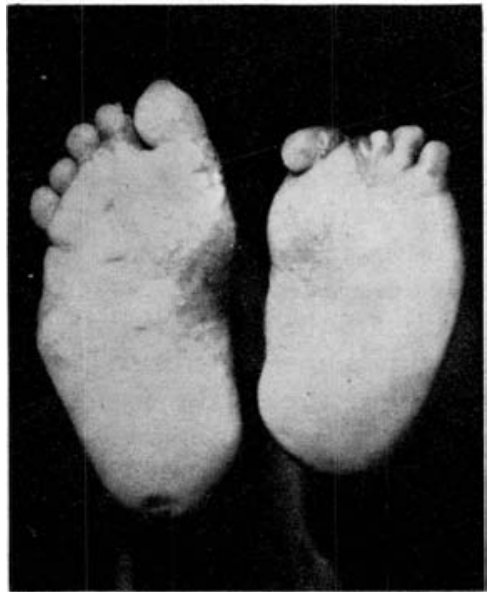

FIG 2

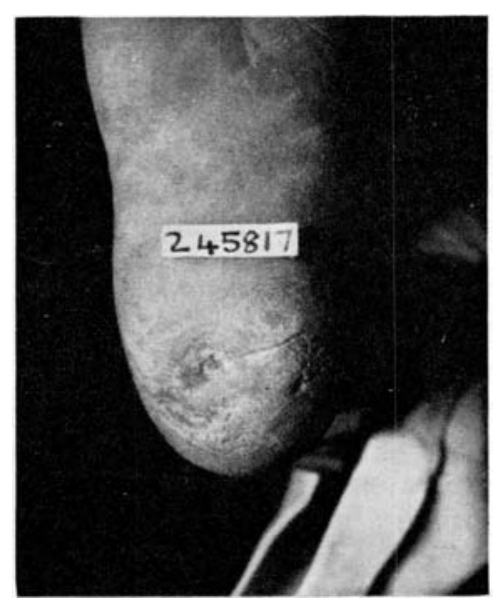

FIG 3

FIG I This heel was extensively ulcerated. The ulcer is healing but the scar is thin and closely adherent to bone. This heel requires trimming of the calcaneum and a direct flap.

FIG 2 The scar on the heel of the right foot has an adherent depressed centre, but mobile resilient margins, and is stable. The antero-medial corner of the left foot contains a plastic sponge implant (See text). FIG 3 This narrow scar has poor resistence to shear: Plastic surgery indicated. 
the plastic aspects of the case.

The following types of scar are notoriously unstable :

(I) Scars over the normal pressure points of the foot, i.e., Heel, heads of the first and fifth metatarsals.

(2) Scars over abnormal pressure points - usually in the badly distorted foot.

(3) Scars which are adherent to bone.

In the heel, we recognise three types of scars:

(a) Extensive scars closely applied to the underlying bone without interposition of plantar fascia. (Fig. I).

(b) Depressed scars in which the base is closely adherent to the bone but with resilient thick margins. (Fig. 2).

(c) Localised or linear scars deeply adherent to bone and extending in depth through a heel fascia of normal thickness. (Fig. 3).

Type (a) allows crushing and necrosis of cells on weight bearing, and therefore breaks down as soon as the patients walks. Type (b) usually possesses sufficient resilience of the margins to allow walking in a microcellular rubber shoe with a closely fitting heel counter. Type (c) withstands weight bearing satisfactorily, especially if a heel-counter is fitted to the shoe, but has poor resistence to shear. Types (a) and (c) generally require plastic surgery.

PLASTIG MANAGEMENT OF OPEN U L CERA TION

Open ulcers are of two types; those which heal satisfactorily with conservative treatment, and those which require skin grafting to accelerate healing and reduce scar formation. It is possible to excise clean ulcers and to treat the defect by one of the measures to be described but in general it is preferable to wait for the ulcer to heal spontaneously. This reduces the risk of sepsis and scar contraction reduces the amount of tissue excised subsequently. Plantar ulcers, once clean, can be split skin grafted as a primary measure, but in small ulcers this is unnecessary and in the larger ulcers it may result in an unstable scar. One experience has been that the principles governing plastic surgery in the non-anaesthetic foot are equally applicable to the anaesthetic foot providing that the 'rules of delay' are respected and that flap ratios do not exceed I : I $\frac{1}{2}$ or 2 .
SPLIT SKIN GRAFTING IN THE ANAESTHETIC FOOT

This is useful as a first-aid treatment for clean granulating ulcers. Most writers (Blair et al., Brown \& Cannon, Ghormley, Lewis), agree that these grafts are successful as a definitive treatment if a pad of normal plantar fascia exists between the graft and the bone. The fascia allows the graft to slide over the bone in response to shear stresses, without rupture of cells. This condition is not met where the graft is placed on a base of granulation tissue. Subsequent contraction produces an adherent scar lacking the elastic quality of the plantar tissues. Bearing in mind the above conditions we have found split grafts to be successful in the leprosy foot under the following circumstances:

(I) In def ects due to loss of skin only, e.g., burns (Fig. 4).

(2) Defects over non-weight-bearing areas (Fig. 5).

(3) As a surface covering after flaps of plantar fascia have been swung in to form a resilient bed.

Srinivasan and Mukherjee report the use of local fascial flaps for the prevention of recurrent ulceration of the heel.

Sites which are particularly suitable for split skin graf ting are therefore the instep, lateral border of the sole, undersurface of the heel when the pulp is intact (Fig. 6), and the back of the heel. At first we took skin from the thigh, but we now use the instep of either the same or contralateral foot.

\section{SCARS OVER WEIGHT BEARING AREAS}

These require excision down to bone, which must then be covered with pulp and skin. Experience with leprosy feet confirms the point stressed by Maisels (I96I) that trimming of the underlying bone enhances the chances of successful weight bearing afterwards, and makes it easier to suture without tension. This is an important part of the repair of pressure sores over the ischial tuberosities and greater tuberosities in paraplegics (Yeoman \& Hardy, I 954), and conditions in the anaesthetic feet are not dissimilar. Bony prominences commonly associated with overlying scars in the leprosy foot are: (I) Spurs on the undersurface of the calcaneus. (2) Prominence under the head of the first 
FIG 4 A large anterior skin defect: Suitable for a split skin graft.

FIG 5 Suitable for split skin grafting.

FIG 6 Superficial heel defects treated by split skin grafting. Pre and post operative condition. Heel now stable in microcellular shoes.

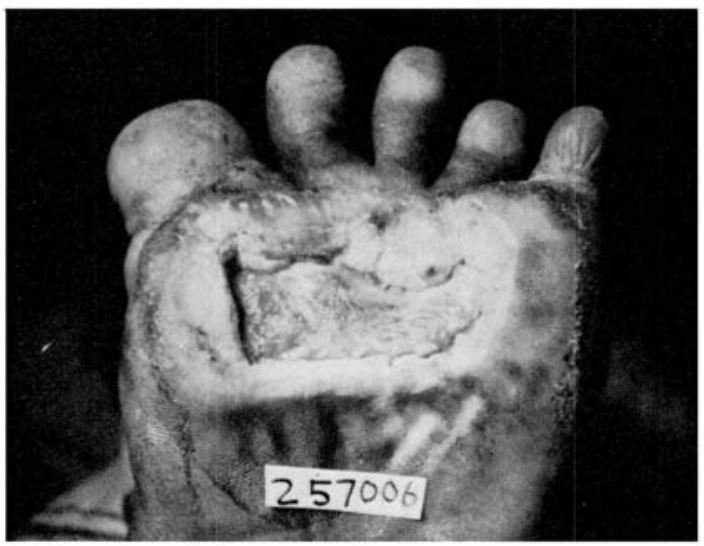

FIG 4

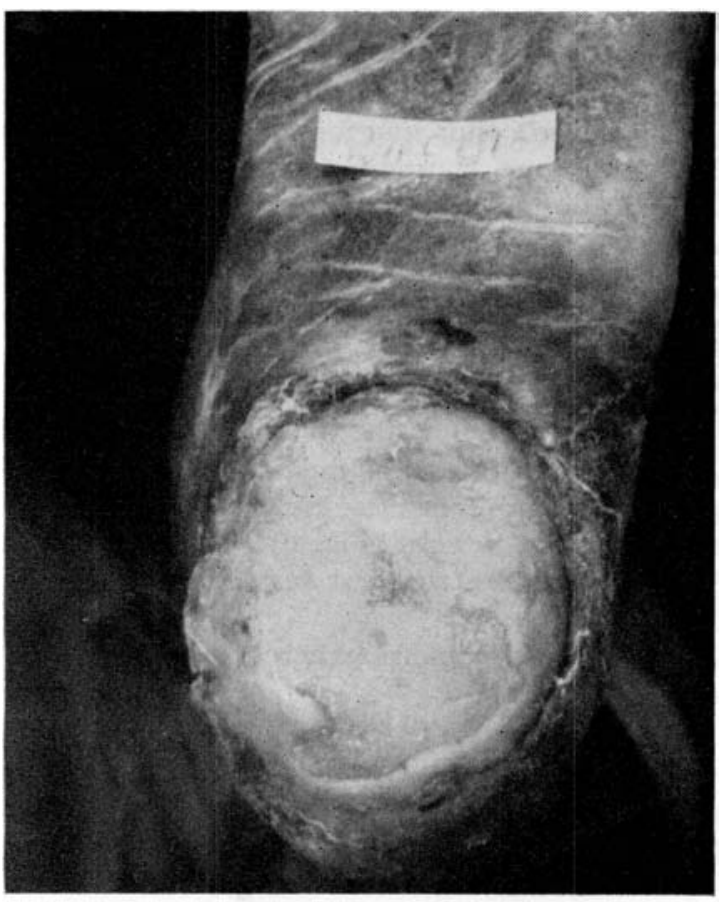

FIG $6 \mathrm{a}$

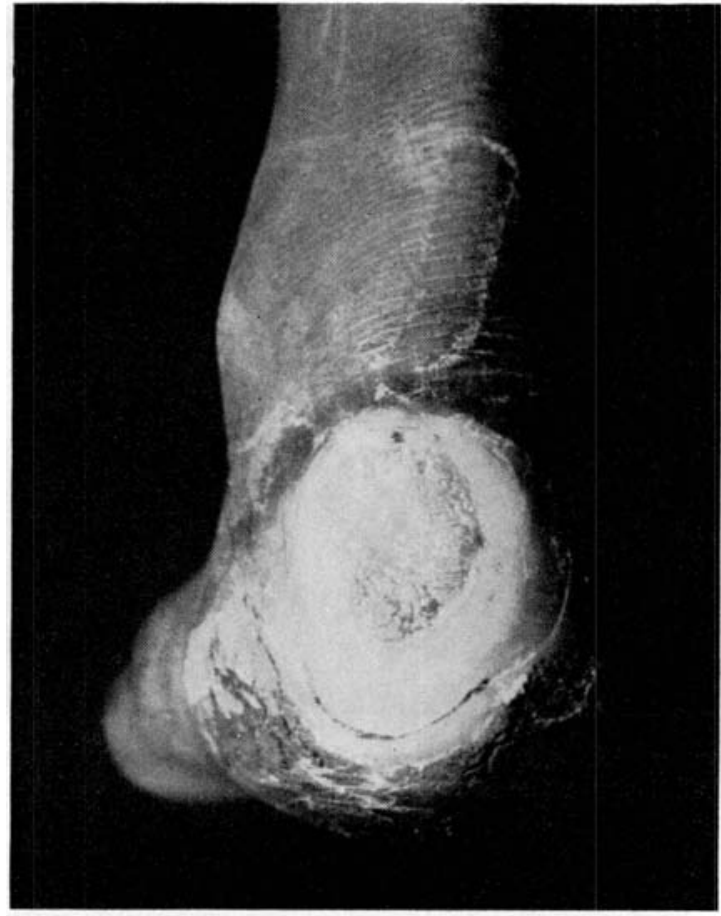

FIG 5

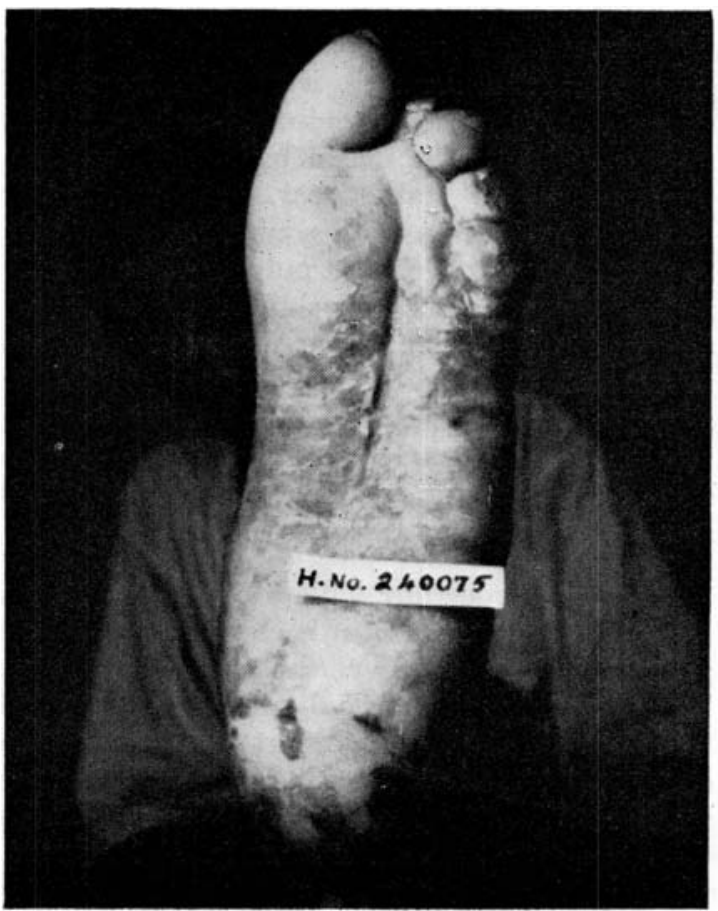

FIG $6 \mathrm{~b}$

Plastic Surgery of the Anaesthetic Foot of Leprosy 


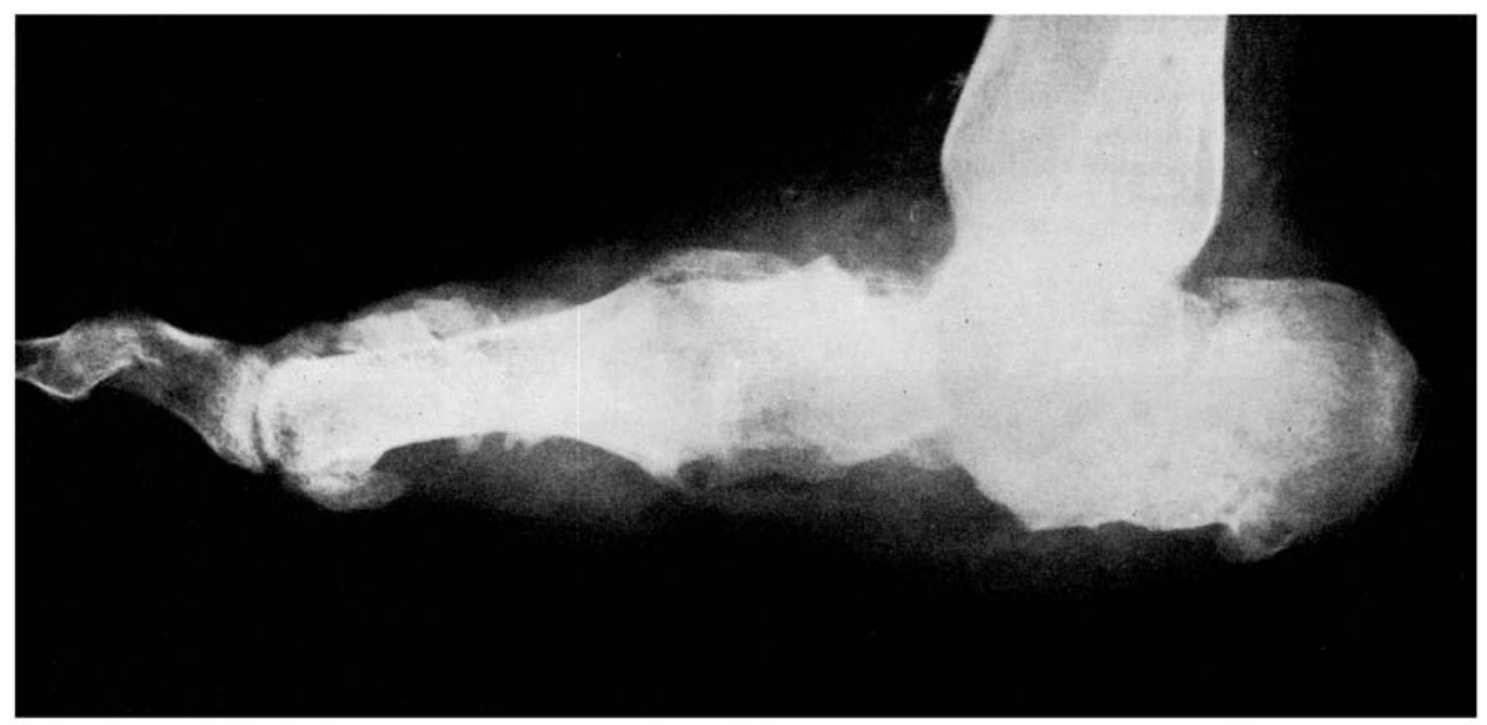

FIG 7 Triple Arthrodesis: Ankylosis of sesamoids to head of first metatarsal creates a localised high pressure point aggravated by ulcer scarring.

metatarsal due to fusion of the sesamoids with the head (old septic arthritis), (Fig. 7).

(3) The base of the fifth metatarsal.

After excision of a scar in depth, a defect remains which requires a flap composed of skin and subcutaneous pulp. Occasionally it is possible to close the defect by primary suture, giving a linear stable scar. This is usually possible in children, and sometimes in adults. It is important to close the pulp layer separately in order to insulate the skin from the bone. Catgut is used for the deep sutures in order to minimise fibrosis. If there is the slightest doubt about tension on the suture line, a flap should be employed. A linear scar well insulated from deep structures by a subcutaneous cushion is stable even on weight bearing areas.

After any procedure which leaves a scar on a weight bearing surface, it is essential to obtain mobility of the skin over the underlying bone. We now carry out gentle digital massage on all fresh scars (employing a circular motion) in order to stretch deep adhesions before they mature. The object is to obtain several millimetres of horizontal skin motion in all directions. During this phase of management the patient is allowed partial weight bearing on crutches.
THE USE OF FLAPS IN THE ANAESTHETIC FO OT

When combined with bone trimming, the use of flaps in the leprosy foot is usually safe and effective. Distant flaps do not have the specialised architecture for absorbing impact and shear, and are thus inferior to local foot tissue. They are time consuming and not devoid of complications. We therefore employ local flaps whenever possible. The rules governing local flaps in the leprosy foot are:

(I) Always shift non-weight-bearing skin to the defect.

(2) All flaps should be larger than would be used in the non-anaesthetic foot.

(3) Use large lateral or medial calcaneal flaps whenever possible, as these are based on anatomically constant vessels. (Fig. 9).

(4) Delay on the slightest suspicion of arterial insufficiency.

(5) Avoid making incisions across weight bearing areas.

We have found the following local flaps to be useful in the leprosy foot:

I. For the forefoot:

(a) Filleted toe flaps (Sangman \& Guidin, Giannini). The scar is excised, and the defect fashioned to triangular shape. A flap is rotated 
back into the defect. The skin of the filleted toe is turned back to cover the defect left by the flap. If the def ect is not large, a partial proximal phalengectomy allows toe skin to slide proximally to cover the defect. The toe is temporarily immobilised with a Kirschner wire.

Feet are not uncommonly encountered in which one or more toes are functionless appendages carrying their own special risk of ulceration from pressure against a shoe. Such digits are ideal sources of pulp and skin.

(b) For scars just proximal to the big toe, the above method is useful, or a medial plantar transposition flap may be tried. Always excise underlying bone, and delay if necessary (Anderson). (Fig. Io).

(c) In more extensive scarring of the forefoot, with prominent metatarsal heads, make a transverse incision just anterior to the metatarsal heads, off the weight bearing area. Remove or trim the underlying metatarsal heads. Partial toe filleting will give closure without tension when particularly bad scars a re-excised at the same time.

(d) In some cases, excision of all the metatarsal heads may be required, so that the operation becomes in effect a conservative transmetatarsal amputation.

\section{REPAIRS OF THE HEEL}

Large heel defects are frequently associated with chronic osteomyelitis of the calcaneum, with sinuses opening on to the sides of the heel. A careful examination is therefore important in every case of heel ulcer, for to graft in the presence of bone sepsis is to invite disaster. In our experience, subacute osteomyelitis of the calcaneum does not do well with conservative treatment, and cases with sinuses, need operative treatment. This consists of excising a generous slice of bone from the undersurface of the calcaneum, taking with it prominences and depressions, and opening up deep bone recesses to the curette. A marginal heel incision (fish mouth) may be used, but we prefer to omit the medial limb of the incision, thus preserving the blood supply from the medial calcaneal vessels. Side sinuses are curetted, and the flap is then sutured back with drainage.

Once infection is controlled, the problem of the unstable scar arises. For scars where the main cause of breakdown seems to be localised adhesion to the bone, trimming of the undersurface of the calcaneum (V.S.), followed by a course of digital massage, is sufficient to render them stable. (Fig. I I). Scars which remain unstable should then be treated by one of the methods now to be described.

(a) MEDiAl AND LATERAL GALGANEAL FLAPS: These have given good results (Fig. 9). But should be large, and delayed.

(b) BUCKET HANDLE FLAP

This is a bipedicle local flap which is swung forward from behind the heel. Maisels points out that the heel can be divided into 3 parts (I) the sole part covered by thick skin overlying the plantar cushion, and normally bearing weight; (2) an area over the back of the calcaneum, structurally similar to the sole part, but not bearing weight; (3) the area overlying the tendo-Achilles, similar in texture to normal skin. This flap brings area (2) into contact with the ground, and the defect over the tendoAchilles is split grafted. The ratio should not exceed I : 2. (Fig. 8).

(c) DIREGT FLAP

These are required when the defect is too large to be covered by a local flap. The main application is for large defects under the heel, but defects of the forefoot can also be treated in this way. These methods are time consuming, involve immobilisation of the patient in difficult positions, and the tissue which is brought in is inferior in quality to the fascia which it replaces. Unsightly scars are also created. However, such flaps give good service in cases where special attention is given to aftercare. Underlying bone should be trimmed. Donor sites include:

The upper $\frac{1}{3}$ of the apposite calf (Ghormley).

The inner side of the opposite thigh (Browne and Cannon).

The buttock.

The selection of donor site depends on:

(I) The availability of blood supply. At levels below the upper $\frac{1}{3}$ of the calf the arterial supply is risky:

(2) The presence of a superficial fascia sufficiently thick and fatty to withstand trauma in its new location.

In Indian patients, this may be a problem. Many who need this operation lack subcutaneous padding. This makes the selection of a donor site difficult. Hence the occasional recourse to a buttock flap. However, we have observed thin 


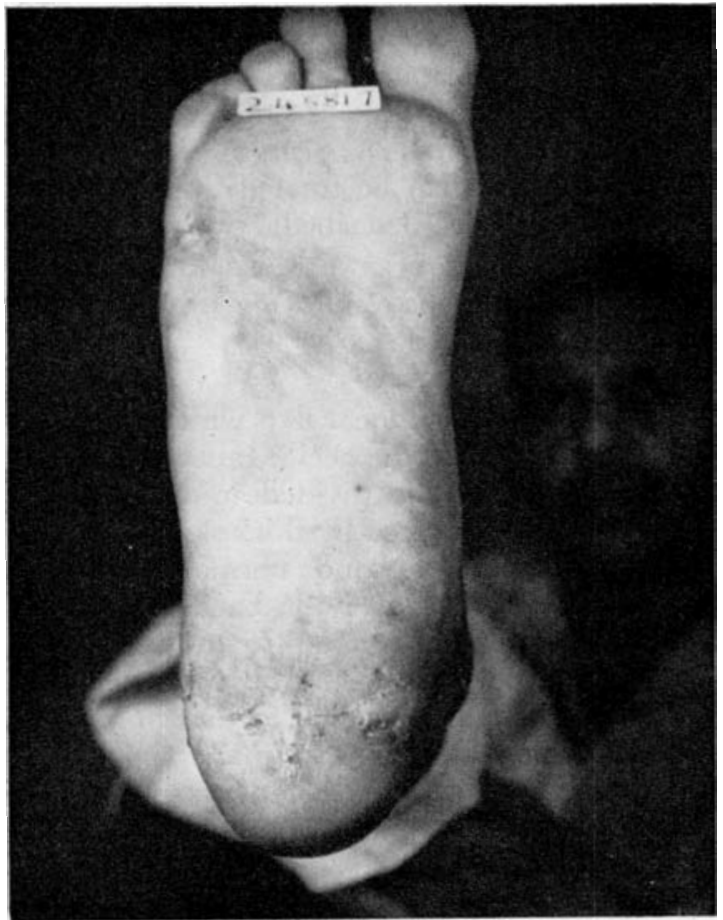

FIG 8 Bucket-handle flap.

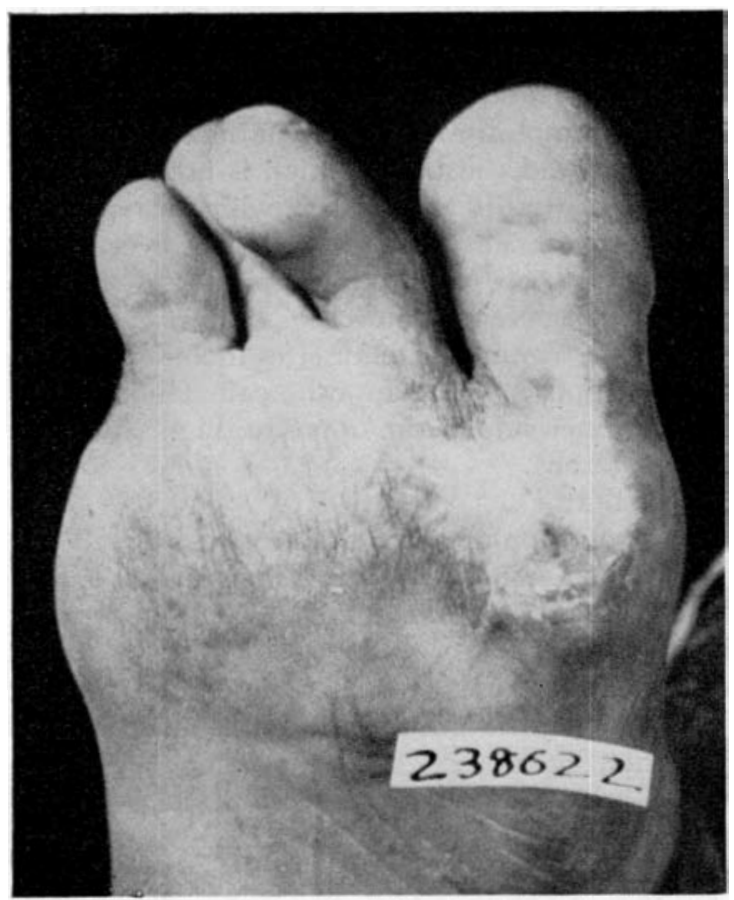

FIG IO An adherent scar under the head of the first metatarsal. Suitable for filleted Hallux flap.

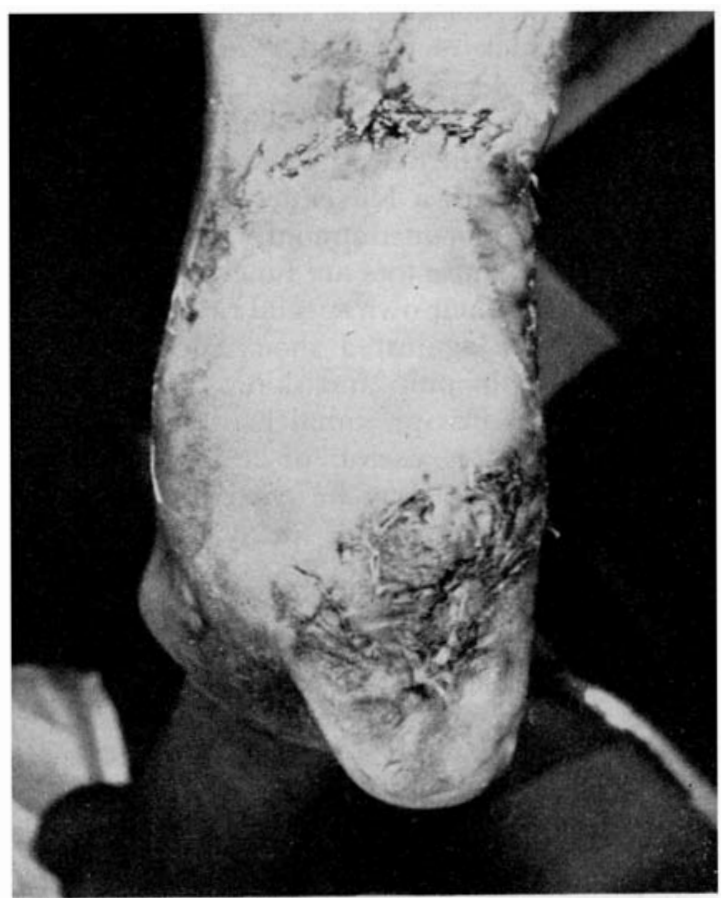

FIG 9 Medial Calcaneal Flap (Ist stage) for heel scar. (Courtesy of Dr. A. J. Selvapandian).

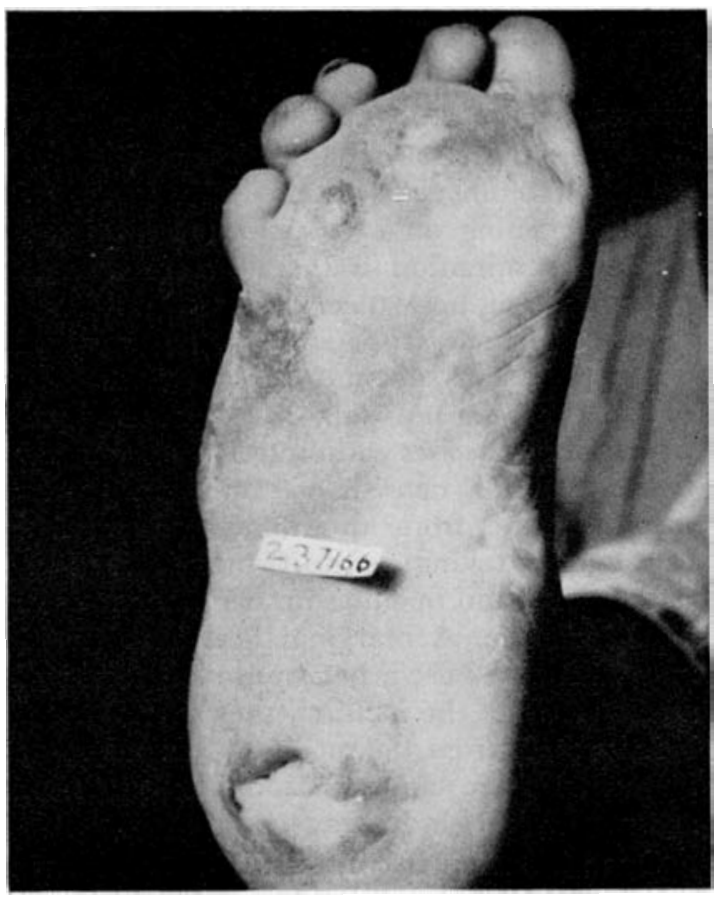

FIG I I A heel scar rendered stable by trimming the calcaneum.

\section{4 Leprosy Review}




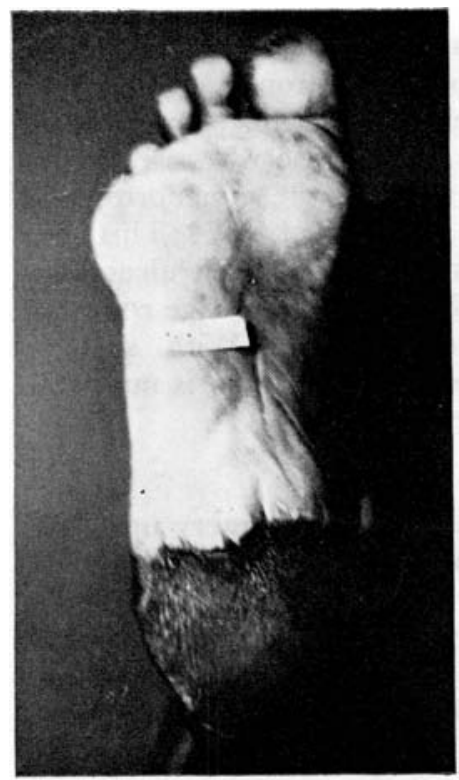

FIG 12

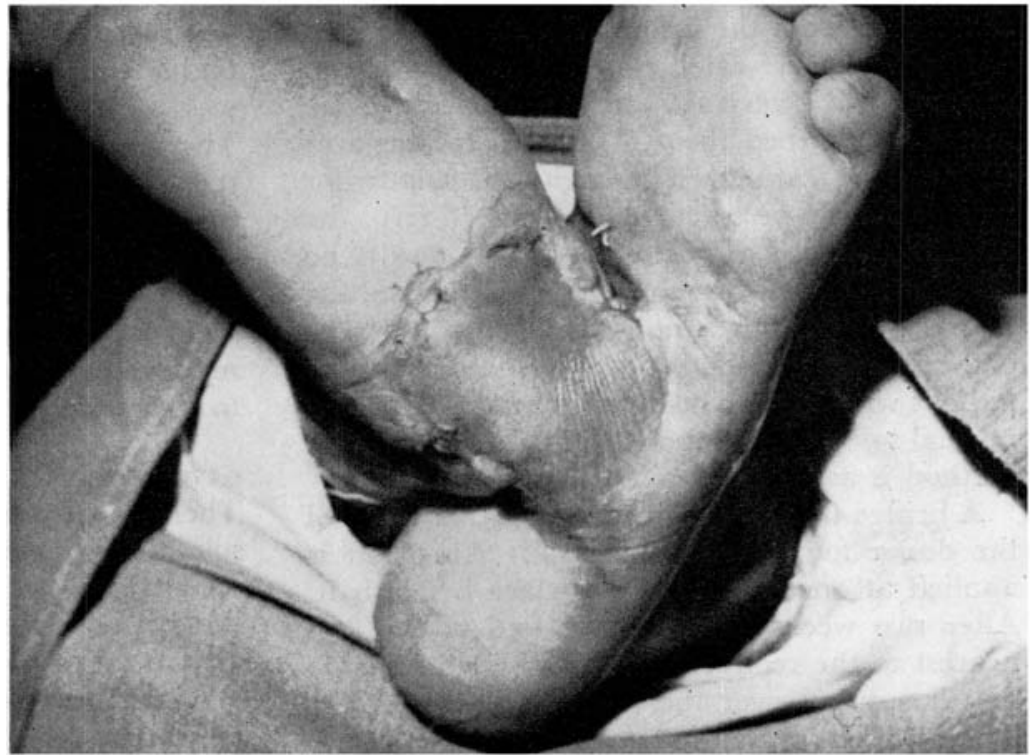

FIG I 3

FIG 12 A cross leg (direct) flap 15 months after the operation.

FIG I 3 A cross plantar flap (MIR-Y-MIR) immediately prior to division of the pedicle.
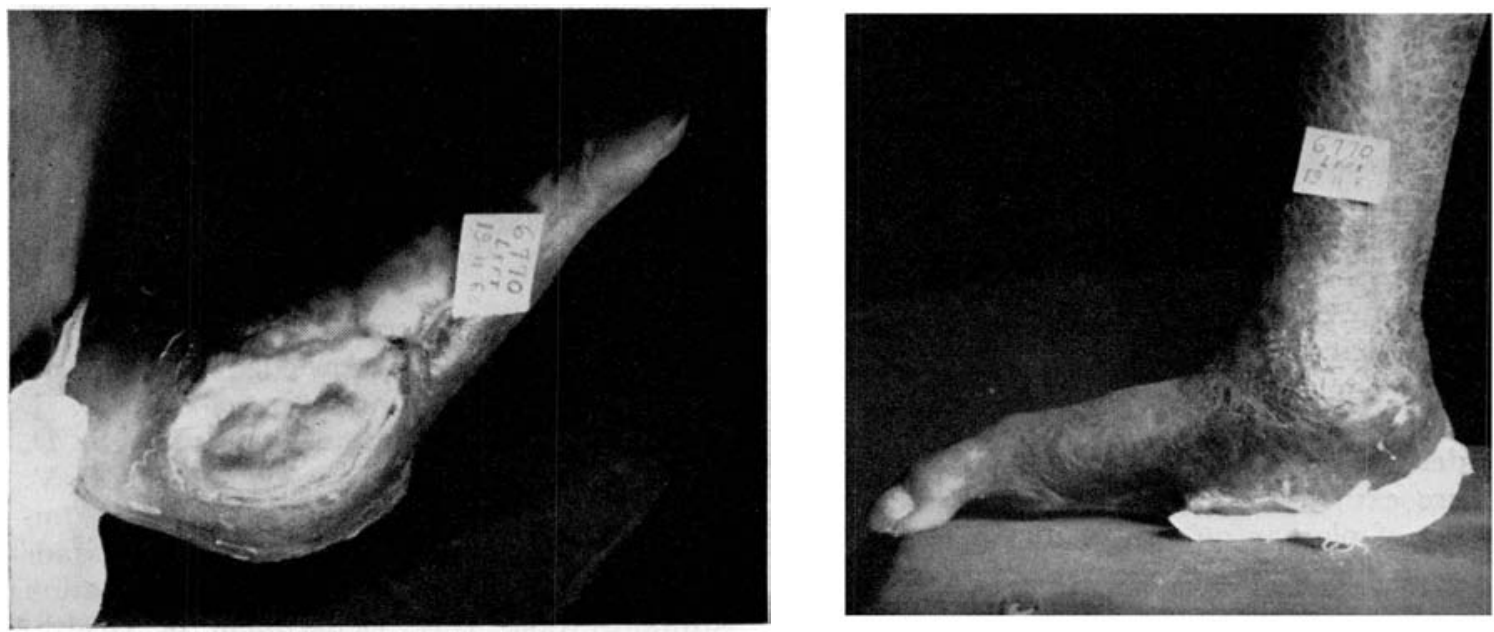

FIG I4 An uncommon reconstructive problem: See text.

flaps which initially adhered closely to bone to become supple and develop a functionally satisfactory subcutaneous layer after about six months from operation. This requires insight and co-operation from the patients, who must understand the need for restricted ambulation until the graft becomes mobile. (Fig. I2). On the other hand, a gratifyingly thick pad will ulcerate in the patient who takes no care. This prompts us to state a third selection criterion.

(3) The patient should be co-operative, and have insight into the problem and into what is being attempted for him.

In I954, Mir-Y-Mir described the use of a 
direct flap from the instep of the opposite sole. The advantages which this method appears to offer make it a very attractive alternative to the methods described above. These advantages are: (i) the tissue transferred has an ideal structure for withstanding pressure and shear; (ii) the technique is not difficult; (iii) there results no functional damage to the donor foot, since the flap is raised from a non-weight-bearing area of the sole. The method appears to be ideal for the patient with a large heel defect and a relatively normal sole on the opposite foot. In outline, the method is as follows.

A bridge flap is fashioned across the instep of the donor foot, and a thick split skin graft is applied at once to the raw surface beneath it. After two weeks ('delay'), the end of the flap nearest to the recipient heel is divided and the flap is sutured over the defect. (Fig. I3). The legs are immobilised in a comfortable position, using plenty of padding for anaesthetic areas. After three weeks the base of the flap is divided, and suture to the recipient heel is completed. Weight bearing may commence about four weeks later.

MISGELLANE OUS PLASTIC PROBLEMS

It is not uncommon to encounter cases in which standard procedures cannot be used. For these it is necessary to devise special procedures. Two examples will be mentioned.

Fig. 2 shows a shortened left foot which was badly scarred anteriorly, but with remnants of toes present. The pattern of absorption suggests neglected claw toes as the cause. In spite of microcellular footwear, ulcers regularly occurred under the anterior end of the first metatarsal, where existed the unfortunate combination of a loss of plantar pulp, and thin scarred skin. Af ter monkey experiments, the underlying bone was trimmed sub periosteally, and a piece of 'silastic' sponge was inserted. The periosteum was united over the sponge with a catgut stitch, and the incision, forward of the scarred area, was closed. The patient has walked on this piece of sponge for io months without further ulcers.

This procedure is not recommended for routine use. Meticulous asepsis must be observed; an infection might well have left the foot much worse than before.

Figure I 4 shows an inverted foot in which ulcers have destroyed the lateral ray. The foot was reduced to a single ray bearing a relatively undamaged big toe at the front. A large ulcer was present under the weight bearing area. The management in this case was resection of the foot skeleton through the cuneiform, and turning back of the filleted flap. This was sutured over the site of the excised ulcer scar. After primary healing a lateral wedge resection and fusion was carried out. With suitable microcellular footwear, this patient is now able to walk without ulcerating.

\section{IS CUSSION}

There is a tendency to avoid surgery upon the sole of the anaesthetic foot, and to rely mostly on footwear (after corrective surgery) to keep the patient free from ulcers. This is a sound attitude, but in certain instances shoes are not enough. It is then that a plastic procedure should be considered. Our experience indicates that much can be done if the known principles of this type of surgery are adhered to. Denervated tissues heal almost as rapidly as normal tissues providing a good blood supply exists: it is this fact which dictates the use of large flaps and broad pedicles.

\section{S UM MAR Y}

Plastic procedures which have been found to be useful in the management of the ulcer prone anaesthetic foot are reviewed. Some of the indications for these procedures are discussed.

\section{A GKNOWLEDGEMENTS}

It is a pleasure to acknowledge the constant encouragement and guidance of Dr. A. J. Selvapandian, and also to thank Mr. S. D. Sigamoney for the photography, and Mr. B. V. Venkatesan for his careful typing of the manuscript. This work was made possible by funds donated by the Vocational Rehahilitation Administration, U.S. Department of Health, Education and Welfare, Washington, and the British Leprosy Relief Association.

\section{REFERENGES}

Anderson, R. A. 'The Treatment of Intractable Plantar Warts'. Plastic and Reconstructive Surgery, 19, 384, 1957.

BLAIR, V. P., BROWN, J. B., BYARS, L. T., 'Plantar Warts, Flaps and Grafts'. Jama, 24, 108, 1937.

Browne and CANNON, Instructional Course Lectures, American Academy of Orthopaedic Surgeons: Vol. 2, 2 I 2, Jan. 1944. GHORMLEY, R. K., 'Functional Graft of the Heel'. Plastic and Reconstructive Surgery, I 02, Jan. I 944. 
Giannini, J. T., 'Surgical Treatment of Plantar Warts, Callosities, and Ulcers'. Plastic and Reconstructive Surgery, r3, I 30, I 954 .

LEWIS, G. K., Instructional Course Lectures, American Academy of Orthopaedic Surgeons, Vol. 2, Jan. 1944.

maisels, D. O., 'Repairs of the Heel'. British Journal of Plastic Surgery, 14, I I 7, I96 I.

mir-y-mir, L., 'Functional Graft of the Heel'. Plastic and Reconstructive Surgery, I4, 444, I 954.
PANGman, w. J. and GURdin, M., 'The treatment of Complicated Plantar Lesions'. Plastic and Reconstructive Surgery, 5, 516, I $95^{\circ}$.

SRINIVASAN and MUKhERJEE, s. M., 'Surgical Management of Chronic Foot Ulceration'. Leprosy in India, 36, I 86, I964. YEOMAN, M. P., and HARDY, A. J., 'The Pathology and Treatment of Pressure Sores in Paraplegics'. British Journal of Plastic Surgery, 7, I 79, I 954. 